COMMENTARY ON COVID-19 AND THE FoOd SYSTEM

\title{
"Let us be small": A case study on the necessity for intentionally small producers
}

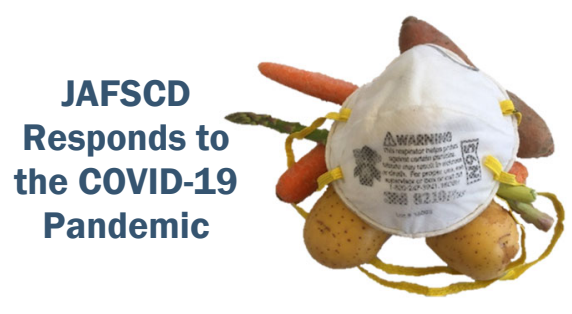

\author{
Alexandria G. Huber* \\ University of North Carolina, Chapel Hill
}

Submitted September 30, 2020 / Published online December 16, 2020

Citation: Huber, A. G. (2020). "Let us be small”: A case study on the necessity for intentionally

small producers. Journal of Agriculture, Food Systems, and Community Development, 10(1), 269-272.

https://doi.org/10.5304/jafscd.2020.101.032

Copyright (C) 2020 by the Author. Published by the Lyson Center for Civic Agriculture and Food Systems. Open access under CC-BY license.

\begin{abstract}
Ran-Lew Dairy quickly adapted during the COVID-19 pandemic, a time when many grocers suddenly faced shortages due to disruptions in their supply chains. Ran-Lew expanded into the direct retail market and increased its in-store sales to stay viable. Due to its small scale, vertical integration, and community connections, it was able to pivot models and react rapidly to the changing needs of its community. This case study highlights the importance of small-scale producers in developing food system resilience.
\end{abstract}

\section{Keywords}

Local Producers, Food System Resilience, Small-Scale Farm, COVID-19, Pandemic, Dairy

\begin{abstract}
A s was the case throughout much of the country, the impact of COVID-19 was felt immediately at 1 Ran-Lew Dairy, a small farm in Alamance County, North Carolina. The farm lost half its business when restaurants closed, and yet it also saw an increased demand for milk from individual consumers as people focused on stocking their pantries. In response, it quickly created a socially distanced on-farm
\end{abstract}

* Alexandria G. Huber, Graduate Student, University of North Carolina, Chapel Hill, Department of Public Policy; aghuber@live.unc.edu

\section{Acknowledgments}

I would like to acknowledge and thank Taylor Hayes, manager of Ran-Lew's Bottling Plant, for allowing me to share the company's story. She worked closely with me throughout the project. 
pick-up system to provide milk to people in the area, expanding into the direct retail market, which it had not previously served (see Figure 1).

In addition to individuals calling to come pick up their milk, larger companies that the farm often provided small quantities of milk to prior to the pandemic also called. Ran-Lew has regularly supplied a small number of bottles to several large grocers in the area. But after the pandemic began and the normal supply chains to these larger grocers faced new strains and needed to adjust quickly, these stores struggled to keep their shelves stocked. Ran-Lew was ready to fill that void. It was able to quickly increase their normal orders to those stores and help make up for losses from the grocers' normal suppliers.

While larger producers and processors were struggling to adjust quickly, causing milk shelves to remain empty across the country, Ran-Lew was able to rapidly adapt its operation and respond, much like many other small-scale producers were able to do. Why?

The size of the farm is partially the reason. With a herd of 50, it is considered a small dairy farm (Figure 2). Randy, the farm owner-operator, remembers growing up during a time when there were around 80 dairy farms

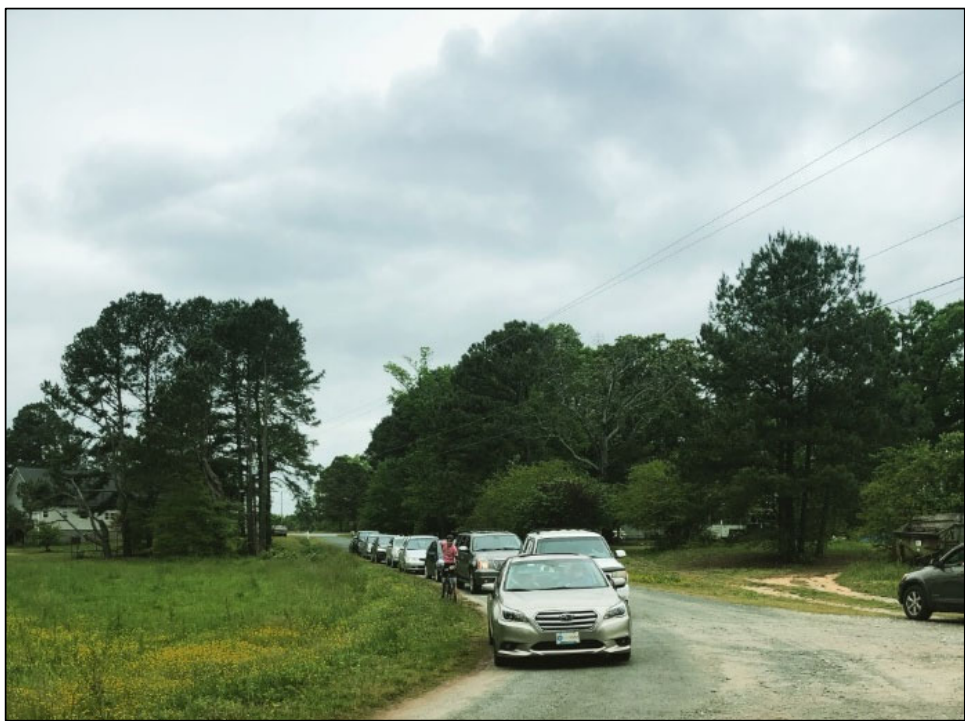

Figure 1. Ran-Lew's Socially Distanced On-farm Pick-up System

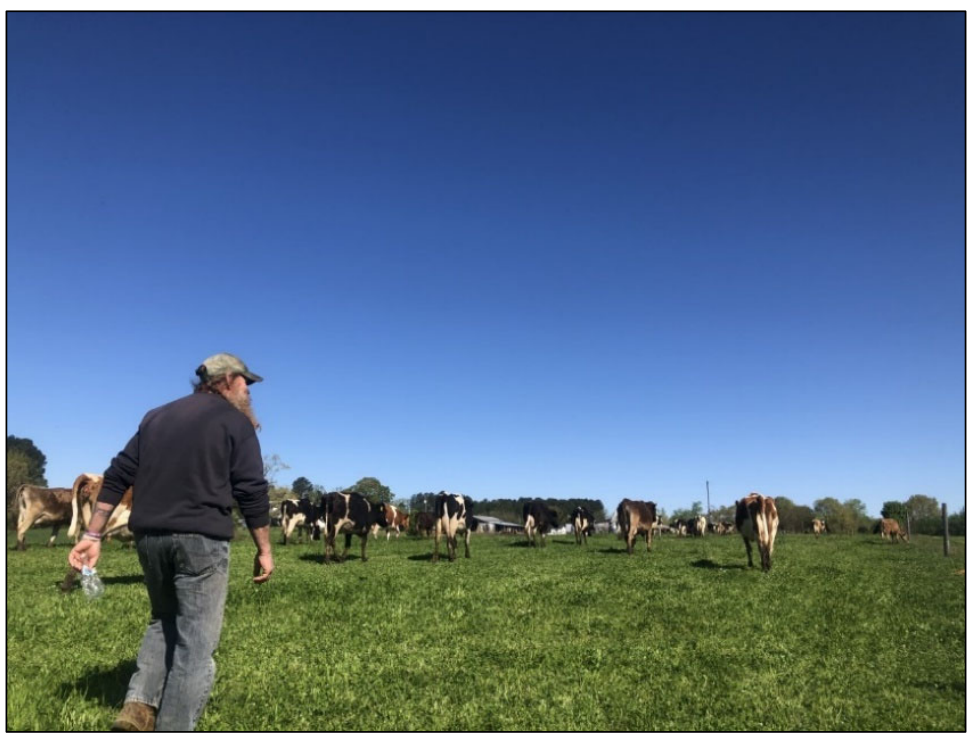

Figure 2. On Ran-Lew Dairy Farm in Alamance County. Now, there are only four. The same trend is being seen across the country. The average herd size grew from 50 in 1987 to 175 in 2017 (MacDonald, Law, \& Mosheim, 2020). Herds of 5,000 , even up to 10,000 , cows are becoming increasingly common (MacDonald et al., 2020). These trends in farm growth and consolidation are the result of a large push throughout the agricultural system, starting in the 1970s with then-Secretary of Agriculture Earl Butz's often quoted phrase to farmers, "get big or get out."

Despite those trends, smaller productions - with their smaller staffs and operations - can be trained more rapidly and can adapt to market changes more fluidly than industrial-scale farms. They are able to pilot novel programs without too large a financial investment and gradually expand those efforts.

Ran-Lew is well positioned for another unique reason: it is vertically integrated. That is, it is fully in charge of its entire supply chain. The company raises its own cows, processes its cows' milk, and 


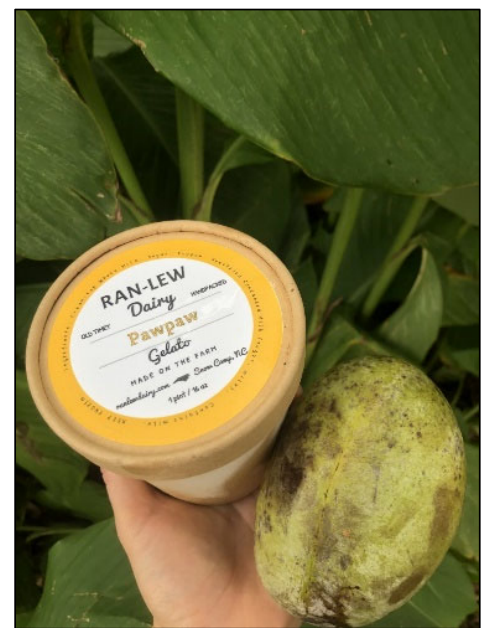

\section{Figure 3. Pawpaw Gelato from Ran-Lew Dairy}

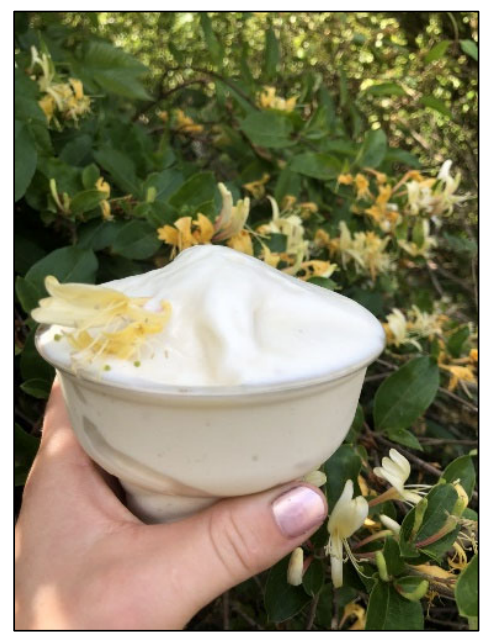

Figure 4. Honeysuckle Ice Cream from Ran-Lew Dairy advertises and sells its own products. This gives the staff greater flexibility to meet larger orders and create new onfarm pick-up systems, as they do not have to rely on large processers as many other dairies do. While this has been critical to Ran-Lew's success, vertical integration alone does not equal resilient, local agriculture. Taylor Hayes, Ran-Lew's bottling plant manager, is quick to point out that Smithfield is an early example of vertical integration that is not resilient, local agriculture (T. Hayes, personal communication, September 2020).

The reliance of small farms on large processors is not unique to dairies.

There has been an increased demand for small- and midscale meat processors as well. Larger processors need large amounts of product in order to be cost-effective, and so they source from a greater number of producers compared to a small or midscale processor. In such cases, producers are often at the mercy of the processor, which can choose which farms to purchase products from. The vulnerability of these farms is only exacerbated by unexpected catastrophes, such as a pandemic.

While larger entities have been able to readjust over the course of months, the COVID-19 pandemic has made the resilience of and need for small producers abundantly clear. When immediate need strikes, these are the operations most readily prepared to respond.

Once retail sales began to return to normal, Ran-Lew was again able to pivot its model to stay afloat in these economically difficult times. Sourcing local, seasonal ingredients, it was able to sell a wide variety

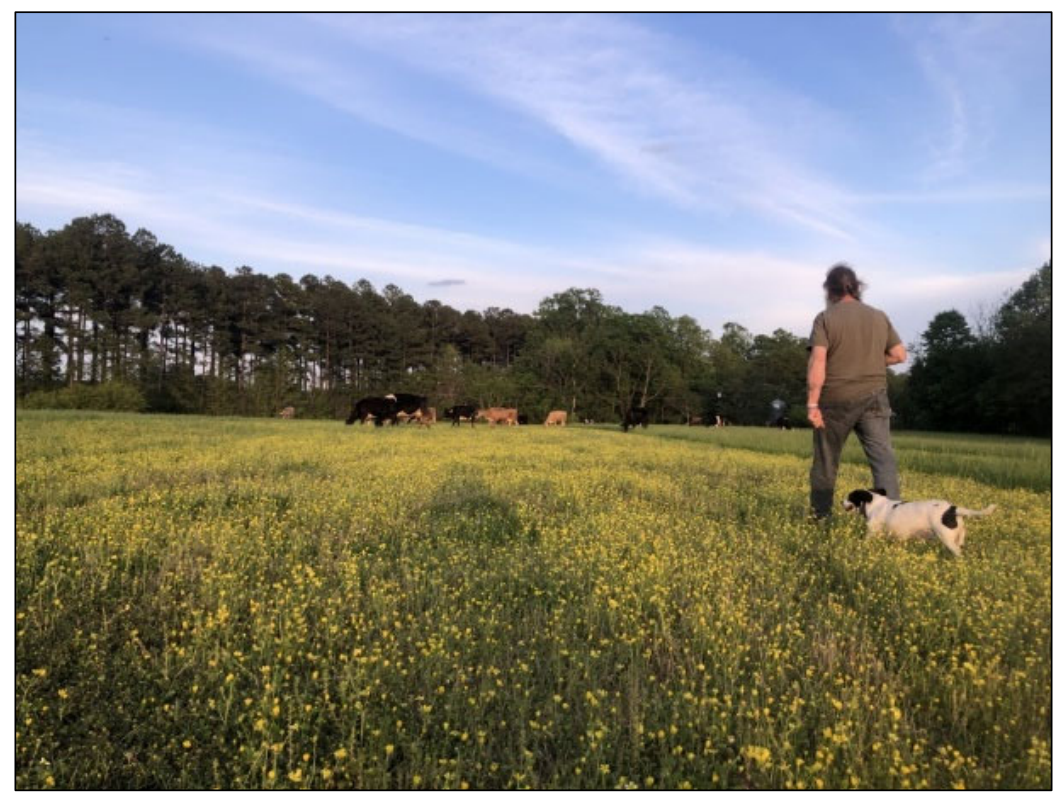

Figure 5. On Ran-Lew Dairy Farm of limited-time ice cream, with flavors including honeysuckle, strawberry, and pawpaw (Figures 3 and 4).

The farm has been heavily engaged with its community for decades, so customers, both companies and individuals, were quick to turn to it when they needed milk during this crisis. To those thankful customers, Randy always responds, "You can't support small businesses only when you need them-you have to support them all the time or they won't be there when you need them" (T. Hayes, personal communication, September 2020).

The resilience of the local food 
economy is crucial to the longevity of our food system. Ran-Lew Dairy exemplifies that resilience, along with other benefits of small-scale production. It is a part of a strong local community with many organizations that are willing to step up and support small and midsize family farms. That support is highly valuable and necessary for the dairy's continued survival. When asked what the largest challenges are for Ran-Lew Dairy Farm in the current agricultural system, Taylor had one request: "Just let us be small" (T. Hayes, personal communication, September 2020).

\section{Reference}

MacDonald, J. M., Law, J., \& Mosheim, R. (2020). Consolidation in U.S. dairy farming (ERS Report No. 274). Retrieved from https://www.ers.usda.gov/webdocs/publications/98901/err-274.pdf 